\title{
Ayar Lloqsimasikunamanta: Una reinterpretación del mito fundacional de los incas
}

\author{
Rodolfo Sánchez Garrafa \\ rodosang@sitiohoy.net \\ UPG de la Facultad CC.SS., UNMSM
}

\begin{abstract}
Resumen
Esta es la primera parte de un trabajo que explora algunas estructuras simbólicas del conocido ciclo mítico de los hermanos Ayar. El autor asume que este corpus mítico legitimaba el ejercicio del poder por los gobernantes incas y que su argumento habría formado parte de la base ideológica del sistema mágico-religioso oficial en la etapa constitutiva del Tawantinsuyo. En consecuencia, propone su reinterpretación como una teoría del poder político, y cuestiona las ideas comúnmente manejadas que entienden este ciclo mítico sea como el memorial de una gesta militar o como alegoría de actividades agrícola, alimentaria y culinaria. Encuentra respaldo en las propias crónicas, así como en otras fuentes etnohistóricas y etnográficas que muestran el mito como una construcción teórica y una expresión normativa de la organización política en los orígenes del Estado inca.
\end{abstract}

Palabras clave: Mitología andina, ideología y política, desarrollo del Estado Inka, gobierno sacerdotal.

\begin{abstract}
This is the first part of a work that explores some of the symbolic structures of the well-known mythical cycle Los Hermanos Ayar. The author assumes that this mythic corpus legitimized the exercise of power by the Inca governors and that its argument would have comprised the ideological base of the magical-religious official system in the constituent stage of the Tawantinsuyu. Consequently, he proposed his reinterpretation as a theory of political power, and discuss the ideas commonly understood that handled this cycle like a mythical memory of a military deed or as an allegory of agricultural, maintenance and culinary activities. He finds support in the same chronicles, and in other ethnohistorical and ethnographic sources, which show the myth as a theoretical construct and an expression of the political organization in the origins of the Inka State.
\end{abstract}


Key words: Andean mythology, ideology and politics, development of the Inka State, priestly government.

Un amplio conjunto de relatos prehispánicos, que tratan sobre el origen del mítico progenitor de la dinastía gobernante cusqueña, configura el ciclo de Los hermanos Ayar. Según estos relatos, cuatro parejas de hermanos «Ayar Manco, Ayar Cachi, Ayar Uchu, Ayar Auca, y sus respectivas mujeres» salen de una paqarina regia, una cueva llamada Tamput'oqo en un lugar conocido como Paqareqtambo. Las cuatro parejas emprenden viaje hacia el norte, y experimentan diversas vicisitudes. Ayar Manco y sus cuatro hermanas logran llegar al valle del Cusco, donde se produce la fundación de la capital imperial y se establece un nuevo orden dinástico por los incas (Urbano 1981; Bauer 1992: 46). Señalados como ancestros de los gobernantes del Tawantinsuyo, los Ayar constituyen el primer eslabón de una cadena mítica que se prolonga en la relación de gobernantes «qhapaqkuna» o 'dinastía de los reyes incas'.

El argumento en cuestión debe haber formado parte de la base ideológica del sistema mágico-religioso oficial en la etapa constitutiva del Tawantinsuyo. Con mucha razón dice W. Espinoza (1997: 298) que los mitos de los Ayar y el de Manco Cápac “... constituían, en definitiva, la 'ley' o 'carta magna' que legitimaba el ejercicio del poder desplegado por la casta Inca residente en el Cusco". Es de verse que los pormenores del ciclo de «Los hermanos Ayar» explicitan un discurso sobre el culto a Wiraqocha y otras wakas principales de los incas y, por lo tanto, es plausible que el mito de los hermanos Ayar haya ocupado lugar preponderante en la transmisión de información distribuida a los funcionarios del culto oficial; concurrentemente, este corpus mítico debió ser un elemento más de legitimación del poder detentado por la clase sacerdotal, y un referente para la coronación de los sucesivos gobernantes.

En tiempos fundacionales, la organización sacerdotal de los incas del Cusco fue probablemente análoga a la de los demás grupos étnicos de la región, dentro de un sistema general y más amplio de culto a las wakas, reproducido a nivel panandino y quizá continental. En principio, unos especialistas chamanes debieron concentrar los "saberes" (prestigio mágico, poder sanatorio, transmisión y perfeccionamiento del pensamiento especulativo), el "don de la visión" y, por tanto, la capacidad de comunicación directa con las deidades. Es lógico que los iniciados en este quehacer pasaran a cumplir funciones diferenciadas y a ocupar distintos rangos en una escala sacerdotal cada vez más jerarquizada, conforme a la creciente complejidad que adquirían las estructuras de poder.

Dentro de este marco hipotético, proponemos una reinterpretación del ciclo de Los hermanos Ayar, acudiendo a referentes de orden etnohistórico, etnográfico y filológico. Las reflexiones que siguen son producto de un largo proceso de maduración, que empezó con una primera intuición sobre el carácter singular del corpus mítico correspondiente. La intención es contribuir a explicar, con evidencias, la coherencia mutua que manifiestan los diferentes elementos del relato mítico, y su integración en la lógica de un discurso que vincula la esfera mágico-religiosa con el ejercicio del poder político.

\section{Los hermanos Ayar: una teoría sobre el poder político}

La mitología andina es ciertamente “... un camino privilegiado para entender al hombre y a la sociedad andinos" (Marzal 1979). Esto no significa, sin embargo, que debamos tomar a los mitos como un registro de acciones reales desarrolladas en tiempos remotos. Lo que en verdad interesa descubrir no es la historicidad de los hechos que 
relatan los mitos, sino la visión que los hombres se forjan sobre el mundo y la sociedad, y que se trasunta mediante este discurso.

Los cronistas del siglo XVI creyeron en la existencia real de los hermanos Ayar, aunque calificaron de supercherías, disparates, desvaríos y mentiras a los relatos que llegaban a sus oídos. Algunos historiadores de nuestra época todavía consideran a los hermanos Ayar como personajes históricos, siguiendo el criterio paradójico que se impone a partir de la llegada de los españoles y la subsecuente conquista del Tawantinsuyo.

Con independencia de su ya cuestionada "historicidad", el ciclo de Los hermanos Ayar selecciona gestos que atribuye a uno u otro de sus personajes, expresando acciones-modelo o arquetipos de un orden social en el que la legitimidad del poder político se sustenta en consideraciones de orden sobrenatural o del designio divino. De este modo, los relatos de origen o fundacionales del Estado Inca perfilan una teoría del poder, ya que "... el ciclo mítico de los [hermanos] Ayar, a semejanza de cualquier otro discurso mítico, quiere convencer a los que lo escuchan de la legitimidad de aquéllos que lo producen" (Urbano 1981: XX).

¿Cuáles son los rasgos particulares de tal teoría del poder? Para avanzar en la respuesta, es preciso discutir de entrada algunos conceptos comúnmente aceptados con relación al ciclo mítico de los hermanos Ayar:

- Los mitos fundacionales del Imperio de los Incas han sido interpretados tradicionalmente como el memorial de una gesta militar.

- Los Ayar les quitan las tierras y agua a los Huallas que se desplazan, derrotan a Capalimayta y Sahuasiray y ocupan el área comprendida entre dos ríos (Sarmiento de Gamboa [1572] 1988: 60-61).

- "El Imperio del Tahuantinsuyo se forjó con las conquistas emprendidas por una tribu establecida en el Cusco. Ésta fue adquiriendo poder entre las vecinas, a partir del siglo XIII D.C.” (Kauffman 1975: 483).

- "Al colocar su lugar de origen fuera del valle del Cusco, los gobernantes incas se retrataron a sí mismos como los poderosos conquistadores de la región, que habían vencido a los pobladores locales y ganado el derecho a gobernar" (Bauer 1992: 63).

- "Después que los Incas edificaron, el primer templo del Sol en Huanacaure, se trasladan a la hoyada del Cusco en donde fundan la ciudad; después de guerrear con las belicosas tribus establecidas en el valle" (Harvey 1994: 30).

- Una segunda interpretación, que se difunde también de modo corriente, considera que los hermanos Ayar son personajes simbólicamente ligados con elementos de las actividades agrícola, alimentaria y culinaria y, más específicamente, con el hallazgo de especies alimenticias. Esta interpretación se ampara en etimologías quechuas aparentemente obvias, cuya pertinencia fue aceptada sin mayor reparo desde la llegada de los primeros españoles al territorio tawantinsuyano.

- "Uchu significa ají. La región de Tampu está relacionada con el cultivo de este condimento. Cachi es la sal, y las grandes salinas las teníamos en Maras" (Valcárcel 1959: 165); “Ayar (quinua amarga) es el símbolo del origen remoto, la región del Collao, y es también la sustancia de la preservación del cuerpo, empleada por los momificadores" (Varcárcel, id.: 166).

- "Las parejas simbólicas de los cuatro hermanos Ayar, que parten de la posada de la aurora o Pacaritampu, con sus alabardas resplandecientes y sus hondas que derriban cerros, van a buscar la tierra predestinada para implantar en ella el maíz y la papa, nutricios de la grandeza del imperio. Ellos mismos simbolizan, según Valcárcel, el 
hallazgo de algunas especies alimenticias: Ayar Cachi, la sal; Ayar Uchu, el ají; Ayar Auca, el maíz tostado" (Porras 1973: 21).

- "La etimología de Ayar Cachi no ofrece dificultades pues cachi es la voz para la sal, condimento por excelencia para el hombre. En cuanto a uchu, además de quinua silvestre significa ají, nombre impuesto por los españoles para el Capsicum sp., cuyas variedades fueron las principales especias del Nuevo Mundo. El nombre del tercer Ayar, llamado por los cronistas Mango o Manco, se refiere posiblemente a una planta alimenticia caída en desuso: mango, antiguo cereal (Bromus mango) prácticamente extinguido (...). La denominación de Auca, el cuarto hermano, está relacionada con una actividad guerrera y no con una planta o condimento" (Rostworowski 1988: 27).

- "Los etnólogos creen que los nombres de los cuatro hermanos Ayar representan productos alimenticios, introducidos o preferidos por ellos, cuando ingresan al Cusco: Ayar Cachi, representaba la sal, Ayar Uchu el ají y Ayar Aucca el maíz tostado" (Harvey 1994: 23).

- Finalmente, en la actualidad, se intenta una comprensión más sustantiva del ciclo de los Ayar. Una de las más recientes propuestas estima encontrar en este mito la expresión de un modelo trifuncional, de acuerdo al cual los principales personajes se asocian funcional y diferenciadamente dentro de un esquema de representación global del mundo andino precolombino; Manco estaría asociado con la función del señorío político, $U c h u$ con la función ritual o del culto, y Auca con la función agrícola (Urbano 1981: L). Desde otra perspectiva, un planteamiento sugerente considera a este ciclo mítico como una construcción teórica y una expresión normativa de la relación entre los límites geopolíticos y sociales en la organización global del imperio (Urton 1989: 172).

Pese a estos encomiables esfuerzos, se mantiene pendiente la tarea de identificar derroteros viables y más productivos que ayuden a explicar el discurso global contenido en el ciclo de los hermanos Ayar.

A nuestro juicio, es erróneo -o al menos, sesgado- considerar que el mito de los hermanos Ayar sea la narración de una gesta guerrera; por el contrario, el argumento del mito, sus temas y motivos centrales, conciernen de manera evidente a espacios sagrados, relaciones e intercambios con el mundo sobrenatural, gestos y dominio de curacas sacerdotes. En cuanto al intento de aparear personajes con especies alimenticias, es de verse que se ensaya forzadas soluciones, sobre todo en los casos de Auca y Manco. Tampoco son convincentes las supuestas correlaciones del tipo Awqa-guerrero, Kachi-cocina, Uchucomercio, diversificación artificiosa que carece de marco etnohistórico y no se sustenta en el contexto del propio mito.

Bien se ha dicho, que “... las traducciones hechas por los cronistas de los nombres de los personajes son inexactas, no expresan las realidades semánticas de los vocablos, se pliegan más bien a los intereses ideológicos y políticos perseguidos por cada uno de los autores" (Urbano 1992: 265). No podía ser más contundente esta apreciación -que compartimos en términos generales-, aunque consideramos que Urbano también tropieza con dificultades que en algún momento le llevan a interpretaciones dudosas, como la de Cachi que hemos de examinar en este trabajo, la de Arnauan (Urbano 1991: 125), y las de Tauapaca y Taparaco (Urbano 1981; y 1988: 135), que esperamos discutir en otro momento. Pero veamos, en orden a la tesis del mito como expresión de una teoría del poder, algunos antecedentes ideológicos importantes de la organización política inca. 


\section{Ideología de base y reestructuraciones político-religiosas}

La hegemonía alcanzada, en su respectivo momento, por las naciones Tiawanako, Wari e Inca, fue precedida y acompañada por reformas religiosas, concurrentes, en cada caso, al propósito de instituir la primacía de sus deidades étnicas particulares. Tales reestructuraciones establecieron, a su turno, nuevas jerarquías en el sistema de creencias y de culto general a las wakas.

Los mitos de Tunupa, por ejemplo, expresan importantes reestructuraciones, acordes con la maduración de fuerzas tendientes a cohesionar una hegemonía étnica en la región del Collao. Tunupa es señalado como predicador de una doctrina que entra en contradicción con el culto a las antiguas wakas. A la manera de otras deidades andinas mayores, Tunupa es un kamaq o animador, que pone en cuestión la vigencia igualitaria de las múltiples wakas del mundo andino pre-inca.

Conforme al mito, Tunupa persigue a las wakas ancestrales del sur andino, destruye algunas y ahuyenta a otras, obligándolas a refugiarse en las partes altas (en las lloqes y qenamaris como el Awsangate). Al parecer, un proceso similar afectó la región de los Wari, pues la tradición oral respectiva refiere que Tunupa Warivilca expulsó a las wakas de esa región, confinándolas en las alturas de Pariaqaqa y Wallullo.

Los mitos de Tunupa refieren reestructuraciones religiosas que empatan con mitos de origen conformados con anterioridad. Tunupa, el actor de la nueva doctrina religiosa, se manifiesta como "animador" o kamaq que infunde vida a bultos hechos de piedra. El paso de lo inerte a lo vital se produce en las paqarinas.

Las rutas de Tunupa o Tunupa Wiraqocha sugieren espacios de influencia y expansión de la correspondiente reforma religiosa, cuyos ecos alcanzan hasta el período inca PrePachacuti, en el que la clase señorial del Cusco logra instaurar su propia hegemonía. El ciclo de los hermanos Ayar expresa, por su parte, y de manera particular, algunos de los extremos de la reforma religiosa que instrumentaron los qhapaqkuna o señores del Cusco para afirmar su poder.

"Hecho prisionero (Copalimayta) en un combate fue obligado a abandonar sus tierras para salvar la vida, y se despidió de los suyos diciéndoles: Adiós, cuando en adelante apercibáis la cumbre de las montañas cubiertas de nieve, podréis decir: allí está desterrado el infortunado Copa Limayta" (Cabello Valboa, cit. Valcárcel 1939: 195).

El relato que antecede parece hacer referencia al desplazamiento de una waka llamada Kopa Rimaq (La piedra preciosa que habla o el Oráculo de la esmeralda). Entre las piedras preciosas o umiña, la esmeralda tiene un prestigio adivinatorio universal, como dice una antigua referencia: “¿Y qué dicen tales sabios de la esmeralda? ¡Ah! que nos hace conocer lo futuro, como si fuéramos profetas del Altísimo: Cómmodus iste laps scrutántibus ábdita fertur, quum proescire volunt aut divinare futura" (Hermo 1899: 128).

La reforma impulsada por los qhapaqkuna del Cusco, radical en un primer momento, debió flexibilizarse más adelante, cuando el culto a las antiguas wakas dejó de constituir un factor capaz de amenazar su estabilidad, esto es cuando el nuevo orden llegó a ser capaz de plasmar su entropía. La práctica ritual de transportar bloques de hielo (los carámbanos de los nevados a que alude Santa Cruz Pachacuti), que persiste hoy en la fiesta de Qoyllurit'i, representa simbólicamente el retorno o reivindicación, así sea temporal, de las antiguas wakas o deidades desaforadas por Tunupa y refugiadas en las alturas del Awsangate (Sánchez 1995: 182).

Es de destacar que el ciclo de los Ayar conecta, de modo explícito, con la reforma atribuida a Tunupa. En la versión de Santa Cruz Pachacuti, Apotambo (visiblemente una deidad tutelar, un apu considerado progenitor de los hermanos Ayar) recibe el topayawri, 
un bastón de oro, de manos del propio Tunupa Viracocha. La aparición de los héroes Ayar en Tamput'oqo replica literalmente el poder animador del dios Viracocha, pues es por mandato divino que ellos emergen en aquella paqarina.

En los mitos fundacionales del Cusco, la waka Vilcanota o "Casa del Sol" (de las voces aymaras willk $a=$ sol y $u t a=$ casa) representa la base de una doctrina religiosa reformista originada en tierras altiplánicas. Los relatos explicitan que el mensaje portado por los hermanos Ayar fue entendido y aceptado por los sacerdotes de las principales wakas del antiguo entorno cusqueño. Tal el caso del sacerdote de Saño, quien reconoce la validez del mensaje cifrado en el topayawri (la vara que Tunupa Wiraqocha había entregado a Apotambo, padre de los Ayar) sometiéndose, en su virtud, a la autoridad representada por sus portadores.

“... el cual (Tunapa) dizen que dio un palo de su bordón al dicho Apotambo, reprehendiendoles con amor afable, y por el dicho Apotambo los oyeron con atención, reçebiendole el dicho palo de su mano, de modo que en vn palo los reçebieron lo que les predicaua, señalandoles y rayandoles cada capítulo de los rrazones" (Pachacuti [1613] 1993: 189).

"Hizo su concierto (Apomancocapac) con sus hermanos para buscar tierras, tomando sus bestidos rricos y armas, sacando aquel palo que abía dejado el dicho Tunapa, el cual palo se llamó tupayauri" (Pachacuti, id.: 194).

“... que si no obieras traydo aquella bara que os dejó aquel viejo boçenglero, no os perdonara" (Pachacuti, id.: 105).

El mito de los hermanos Ayar puntualiza la identificación de un nuevo centro religioso, a partir del cual va a organizarse el espacio dominado por los incas del Cusco. Desde Wanakawri marcaron la tierra, para "ordenar los cerros" en el horizonte (Zuidema 1989: 517). Es fácil colegir que el ordenamiento de los cerros concierne a la organización de las wakas en el sistema de seqes. La asociación mítica de la waka Wanakawri con Turumanya o Yayaqarwi (el Arco Iris), define su condición ideal como lugar de distribución de la tierra o Kamaqpacha.

"Llegaron a un cerro, llamado Huanacauri (al cual después por ocasión desta fábula tuvieron los indios por adoratorio célebre), y desde allí marcó la tierra el hermano mayor (Manco Cápac), y tirando con una honda cuatro piedras hacia las cuatro partes del mundo, tomó posesión della" (Cobo [1653] 1956: 135)

“... y subiendo un día al cerro Guanacaure para de allí mirar y divisar donde fuese mejor asiento y sitio para poblar y subiendo ya encima del cerro Ayarcache que fue el primero que salió de la cueva sacó su honda y puso en ella una piedra y tiróla a un cerro alto y del golpe que dio derribó el cerro y hizo en él una quebrada y ansi mismo tiró otras tres piedras y hizo de cada tiro una quebrada grande en los cerros altos..." (Betanzos [1551] 1999: 18).

Santa Cruz Pachacuti llama Camac Pacha al lugar cercano a Wanakawri desde donde Manco Qhapaq toma posesión de la tierra. Camac Pacha o Kamaqpacha ha sido interpretado como tierra fértil o tiempo oportuno (González Holguín [1608] 1989: 524) $\mathrm{y}$, en el mito de los Ayar, es el lugar de distribución de la tierra, identificado como uno de los "pies" o extremos del arco iris. Adviértase que la voz Camatha, en aymara, quiere decir precisamente: <medir con vara o soga $>$ (Bertonio [1612] 1984: 35), al igual que camattatha y tuphuttatha.

En los mitos de Huarochirí, la honda o waraka es el símbolo de Chutacara (nombre que proviene de Chuta o señal de las leguas, término en cada cien brazas de tierra). De manera análoga, los héroes Ayar aparecen pertrechados con sus respectivas hondas o warakas hechas de nervios, como símbolo del poder que les asiste para tomar posesión y distribuir la tierra. 
Los ancestros epónimos, llamados mallkis (cepa familiar y momia de los antepasados a la vez), están ligados en el pensamiento andino con el vínculo de origen, la protección tutelar, pero también y de manera especial con el acceso a la tierra, el bien de producción por excelencia. En efecto, el nombre de la abuela de los hermanos Ayar: Pachamama achi o Pachamamaachi alude al poder de otorgamiento, distribución y linderamiento de tierras.

Achachi ururi y Apachi ururi, Venus o lucero del amanecer y del atardecer respectivamente, representan en el dibujo cosmogónico de Santa Cruz Pachacuti a los abuelos míticos de los incas, padres de los Ayar. La etimología aymara de estos nombres corrobora la relación de los antepasados con la organización y el ordenamiento simbólico del espacio y también, en este caso, de venus con los seqes en términos astronómicos.

Según Bertonio ([1612] 1984):

Achachi: Viejo, abuelo (Id.: 5).

Achachi:: Término o mojón de las tierras (Id.: 5).

Apachi: Vieja, abuela (Id.: 23).

Apachi: Amontonamiento ritual de piedras (Id.: 23).

De aquí deriva achachila (antepasado mitológico que habita en una colina sagrada), en tanto mojón o señalador de linderos. Análogamente, Pacha achachiq vendría a significar el que amojona la tierra, una de las atribuciones de Wiraqocha, pues hizo de piedra cierto número de gente (Betanzos [1551] 1999: 11), animó a los antepasados y los hizo salir de las paqarinas. Pero también convirtió gente en piedra (monolitos) en Tiahuanaco, Pucara, Jauja, Pachacamac y otras partes (Molina "El Cuzqueño" [1575] 1989: 53).

"Así como salió y en aquella mesma hora, como ya hemos dicho, dicen que (Con Tici Viracocha) hizo el sol y día, y luna y estrellas; y que esto hecho, que en aquel asiento de Tiaguanaco, hizo de piedra cierta gente y manera de dechado de la gente que después había de producir" (Betanzos, Op.cit: 11).

" (y Viracocha) ... fuese a un asiento, que ahora llaman Tiaguanaco, que es de la provincia de Collasuyo, y en ese lugar esculpió y dibujó en unas lozas grandes todas las naciones que pensaba criar" (Sarmiento [1572] 1988: 43).

“... el Hacedor, a quien en lengua de estos yndios le llaman Pachayachachi, y por otro nombre Titiuiracochan, que quiere decir yncomprehensible dios, vino por el camino de la cierra visitando y viendo a todas las naciones, como avían començado a multiplicar y cumplir lo que les avía mandado; y que algunas naciones que alló reveldes y que no avían cumplido su mandado, gran parte dellos convirtió en piedras, en figuras de hombres y mugeres con el mismo traje que trayan" (Molina [1575] 1989: 53).

"Cuentan más que aquellos primeros hombres en aquellos mismos lugares, después de haber dejado sucesión se convirtieron, unos en piedras, otros en halcones, cóndores y otras aves animales; y así son de diferentes figuras las huacas e ídolos que adoraban. (Cobo [1653] 1956: 151).

Desde la base del arco iris, en Guanacauri (Wanakawri), los Ayar determinaron el Valle del Cusco como el lugar donde habrían de fundar su pueblo: el ombligo o centro del mundo al que llamarían Qosqo. Guanacauri es tomado como Kamaqpacha por haberse considerado que la aparición del arco iris era signo de buen suceso, señal de que el mundo ya no sería destruido por el unu pachakuti o diluvio. Cabello Valboa y Martín de Murúa registran versiones similares en este sentido. Según Santa Cruz Pachacuti, fue un doble arco iris la señal que los Ayar consideraron propicia.

"Y un día a el amanecer vieron el Yris (o Arco de el Cielo) que lebantaua el un pie de el mismo cerro y Manco Capac dijo a los demás buena señal es aquesta (...) subamos 
en este cerro y de alli veremos el lugar donde auemos de poblar y permanecer" (Cabello Valboa [1586] 1951: 261-2).

"Y beniendo así, dizen que llego al dicho çerro más alto de todo aquel lugar, y en donde, junto del dicho Apo Manco Capac, se lebantó un arco del çielo muy ermoso de todos colores, y sobre el arco pareció otro arco, de modo que el dicho Apomanco Capac se bido enmedio del arco, y lo avía dicho: «buena señal, buena señal tenemos»» (Pachacuti [1613] 1993: 194).

Luego de varios ensayos en lugares como Wanakawri y Colcabamba (Qolqapampa), los Ayar ubican en Guanaypata (Wanaypata) las tierras más apropiadas para su pueblo, que a la sazón tenían remotos antecedentes de asentamiento humano. Se sabe que el nombre primitivo, de lo que un día sería la Gran Ciudad del Cusco, fue el de Akamama (Guamán Poma [1615] 1993: 31, 66, 67) pero esta denominación no ha sido convenientemente reivindicada. Es probable que alguien haya querido ver en este registro una mala intención de Guamán Poma, por la velada alusión a $A k a=$ herrumbre, estiércol o excremento. Una traducción apurada del vocablo ha llevado a asociarlo con Aqha o chicha. Lo que no se ha tomado en cuenta es que muchos de los lugares sagrados más importantes se asociaron a Jaka o Haka=Vida (Bertonio 1984: 101; Buttner 1984: 66). De manera que Hakamama (el antiguo valle del Cusco), en clara alusión a su inmemorial importancia como lugar sagrado, fue conocido como "Señora o Madre de Vida" (de haka=vida y mama=madre). El culto a los lugares sagrados se enunciaba como haka kutipa apusitha, que quiere decir <adorar las wakas> (Bertonio, Op.cit: 101).

Gracias a la acuciosidad de los que felizmente recogieron su primigenia denominación, sabemos que el Qosqo o Cusco fue considerado desde tiempos remotos "Madre de Vida" "Dadora de Vida" o "Kawsay kamaq", como más propiamente se explicaría en términos andinos.

Acamama: Gran centro ceremonial. Nombre primitivo de la Ciudad del Qosqo de los Inkas o Cusco actual (Guamán Poma 1993: 31; Murúa 2001: 45).

Acapana: Gran centro ceremonial del Tiawanako (Kauffman 1975: 351).

Acacana: Paqarina y waka principal de los indios Paltas junto al pueblo de Cuxibamba (Albornoz 1989: 187)

Kakaaca: Nombre antiguo del nevado Wayna Potosí (Izquierdo 1956: 348).

Quriccaca: Pomo que contenía el qhapaqchana quispesutoq unu o fluido vital del poder (Pachacuti 1993: 211). Se corresponde con el nombre de la ciudad de Juliaca.

En el caso de Akapana ${ }^{1}$, tenemos que -según Cristóbal de Albornoz- es palabra quechua que significa "torbellino", significado corroborado como "remolino de aire y nieve" por Antonio Ricardo ([1586] 1951: 13). Por su parte, Gonzales Holguín traduce Acapana huayra como tempestad de remolino que sube mucho, cuya etimología proviene a nuestro juicio de $h a k a=$ vida y apaña=llevar o arrebatar. En San Pedro de Haca, hacia 1656 (Polia 1999: 166), se denominaba al torbellino con los nombres de acrancui (aqra onqoy) y sococui (soqo onqoy), que parecen derivar de las voces aqra=rajado o aqarapi=nevisca, y soqoy=beber o absorber, a las que en ambos casos se agrega onqoy=enfermedad o estado de frenesí. Estas traducciones son coincidentes, en cuanto a atribuir al torbellino (remolino de aire y nieve) la pérdida o merma de la vida y la situación de enfermedad por absorción, sustracción, quiebre o cuarteamiento del "ánimo" (espíritu o sombra según el pensamiento andino).

1 "Y las más poderosas y sagradas huacas, como son los altos nevados o las cumbres inaccesibles, los ríos impetuosos, los violentos torbellinos de viento, el trueno y el rayo, son ellas mismas hierofanías" (Polia 1999: 107). 
De otro lado, los mitos fundacionales son consistentes en justificar una jerarquización social y presentan un modelo estratificado ideal en el que los Qhapaq, que salieron de Qhapaq t'oqo, se atribuyen una prelación mítica sobre los que se originaron en Maras t'oqo y Sutiq t'oqo. Además, en correspondencia con las alianzas fraternas de los curacazgos regionales, los mitos muestran cómo las wakas locales fueron dando paso a deidades étnicas tales como Vilcanota, Ausancata, Wanakawri. Esto significa un ordenamiento de las wakas y el predominio de algunas de ellas, en torno a un centro sagrado. El mito de Los hermanos Ayar funge de este modo como arquetipo de una reestructuración social y fuente de su legitimación religiosa.

El hecho de que Wanakawri, ancestro mítico de los hermanos Ayar, se convierta en piedra, convalida simbólicamente la pertenencia de ellos a la clase social de los Qhapaq t'oqo. "Aparentemente, sólo las personas de la clase superior podían alegar antepasados tan lejanos como para que se hubieran transformado en piedra" (Zuidema 1989: 121).

En consecuencia, el ciclo de los Ayar condensa un conjunto de elementos simbólicos considerados importantes para la designación de Manko como primer Inca. El virtual primus inter pares resulta elegido de entre cuatro hermanos, con criterios que parecen haber sido observados también en la determinación de sucesiones posteriores.

\subsection{Etapas en el desarrollo del Estado inka y cambios en la estructura del poder}

No incumbe a este trabajo discutir el grado de conocimiento científico alcanzado respecto al desarrollo del Estado inca; sin embargo, será útil a nuestro propósito el pergeñar una breve caracterización, que permita advertir una de las formas de legitimación de las estructuras de poder, tal como se desprende del material mítico disponible.

\section{Etapa del gobierno sacerdotal}

La etapa primigenia del Tawantinsuyo o Pre-Pachacuti, llamada también curacal, se difumina en la leyenda. No obstante, se estima que los señoríos del Cusco, gobernados por curacas sacerdotes, ya estaban constituidos hacia los siglos VII y VIII d.C., y que mantenían su independencia gracias al dominio de los valles de Yucay y Cusco y a sus relaciones con el Altiplano.

Estos pequeños señoríos se sustentaban en ancestrales mecanismos de reciprocidad que tenían al kuraka como su ejecutor principal. Uno de estos señoríos, el de los Qhapaq que daría lugar al Tahuantinsuyo, llega a controlar el Cusco y se nuclea en torno a la cuenca del Vilcanota. Este señorío de los Qhapaq es el basamento originario del futuro Estado inca. Para esta región, ahora parece razonable fijar el inicio aproximado del período Killke (Inca Temprano) en torno al año 1000 d.C. (Bauer 1996: 69).

"Por entonces Acamama era el nombre de una aldea de 30 chozas de pirca y paja, a la misma que se le había dado el apelativo de Cusco" (Espinoza 1997: 32).

"El Estado incásico en el siglo XIII, inmediatamente después de fundado el Cusco, es un pequeño curacazgo en el valle del Huatanay, en pugna permanente con sus vecinos. Su área cubre apenas la ciudad del Cusco y algunas tierras circunvecinas" (Tamayo 1985: 43).

"El Cusco, a lo largo del período en que Wari mantuvo su poder político sobre la región indicada, logró preservar su independencia. Dicha independencia pudo ser gracias a que los señores del Cusco mantuvieron bajo su control una importante y estratégica zona agrícola en el valle de Yucay y en el valle mismo del Cusco" (Lumbreras 1977: 48). 
Al sobrevenir la pugna por la hegemonía entre los señoríos locales, la clase social de los curacas (kuraqkaqkuna o mayores), cuya característica es su multiplicidad étnica, encontró en el establecimiento de alianzas el medio más apropiado para resolver la contraposición de intereses con los curacazgos próximos. Bajo este signo, prosperaron aldeas semi-autónomas en zonas ecológicas de mediana altura en torno al principal foco poblacional constituido por el valle del Cusco (Bauer 1996: 141). Esta unión de tribus, cuya solidaridad se basaba en lazos de parentesco, estaba determinada por el desarrollo de las fuerzas productivas y, por tanto, se estructuraba con relaciones de producción correspondientes a tal progreso (Núñez Anavitarte 1978: 61). Los pobladores de la región, al parecer alcanzaron la autosuficiencia mediante la explotación simultánea de variadas zonas ecológicas. Así debió aparecer el diminuto Estado inka hacia fines del siglo XII y principios del siglo XIII de nuestra era, como una organización política de carácter estrictamente regional aunque de progresiva tendencia expansiva.

Al imponerse en el entorno cusqueño, el curacazgo de los qhapaq instaura un sistema político-social sustentado en su prestigio religioso, antes que en el poderío militar. El clero era el sector social dominante (Choy 1978: 96) y el basamento ideológico religioso de su gobierno se extendió seguramente hasta el período de confederación quechua o reino regional. El consenso y la tranquilidad reposaban en un bien estructurado y jerarquizado sistema de wakas y en relaciones de reciprocidad perfectamente establecidas. Coherente con una religión que se asentaba en el culto a los antepasados, la waka Wanakawri ocupaba, en principio, una posición de privilegio dentro del sistema general establecido en el valle del Cusco. Es plausible que "...los mascas, chilques y tambos, los incas de privilegio que ocupaban el área al sur del Cusco, estuvieron bajo la influencia o el control de éste en fecha tan temprana como el período Killke, y que la unificación de la región se dio no a través de conquistas militares incas sino mediante medios no-militares de unificación, los que se iniciaron antes del momento en que se dice tuvo lugar la guerra con los chancas" (Bauer 1996: 185).

Los Qhapaq cusqueños pasaron a centralizar el manejo eficiente de una reciprocidad asimétrica para asegurar la lealtad de los curacas tributarios y el cumplimiento de sus obligaciones. El gobierno de los Qhapaq cuzqueños logra afirmar su poder en el ámbito regional, apelando a la solidaridad tribal basada en lazos de parentesco y utilizando la producción a base del trabajo en común. A esta etapa de curacas-sacerdotes corresponde el discurso mítico contenido en el ciclo de los hermanos Ayar.

\section{Etapa del gobierno imperial}

El proceso de consolidación del Estado Inka comprende un período inicial de lucha por el poder. Las clases sociales en pugna se disputaban el control de las instituciones de 'reciprocidad y redistribución', que permitían una apropiación real de la fuerza de trabajo familiar y colectiva. "El Cusco hacia el año 1300 debió estar poblado por una sociedad poliétnica, donde una serie de mercados locales y rivalidades en igual naturaleza mezclaban y separaban los grupos con facilidad" (Millones 1975: 61).

A partir del Inca Pachakuti, la clase política regional triunfante asesta un golpe revolucionario a la clase sacerdotal que hasta entonces había detentado la mayor parte de la propiedad territorial y ganadera (Choy 1978: 96), hecho éste que facilita profundos cambios económicos en la sociedad inca. La hasta entonces emergente aristocracia de los orejones pasa a ser la clase dominante y a tener la mayor participación en el control de las tierras de cultivo y el ganado. En líneas generales, se produce una continua disminución del poder sacerdotal en provecho del Sapan Inca, el mismo que se atribuye el poder de nombrar 
al Willaq Umo y, en ciertas circunstancias, llega a cumplir ambas funciones (Betanzos [1551] 1999: 63; Sarmiento 1988: 84-127).

Con el Inca Pachakuti, el Tawantinsuyo inaugura a fines del siglo XIV una época de expansión cultural violenta y de apogeo del Estado. El Estado imperial post pachacuti incorpora una compleja red de naciones sometidas, de desarrollo desigual y con variadas particularidades. La aparición del Estado Imperial, entidad política supraregional, afirma la hegemonía del Cusco y el poder de las dinastías inkas. Tal situación parece haber sido el corolario de la alianza con los Qollas y de la victoria bélica sobre los Chancas.

El paso a la etapa imperial del Tawantinsuyu está íntimamente asociado a la solarización del culto oficial inca, la disminución o limitación del "poder de los muertos", una mayor importancia del sistema de yana, y la aparición de nuevos objetos de culto a los que la waka Wanakawri tuvo que ceder parte de sus prerrogativas e importancia. Los cusqueños habrían elaborado entonces la imagen de un dios solar dinámico, asimilable a la vocación militar del nuevo Estado, y fundamento de una ideología operativa supraétnica destinada a asegurar los sentimientos de lealtad y sumisión al sapan Inca.

A las exigencias ideológicas de esta etapa corresponde, sin duda, el mito de Manco Qhapaq y Mama Oqllo, creados por el Sol y salidos del lago Titicaca, que al parecer es de origen tardío. Esta nueva versión fundacional habría correspondido a un cambio ideológico subsecuente al ingreso en la etapa imperial con la alianza incas-qollas que se impone al reino chanca. Del mito solar, que Garcilaso de la Vega hizo conocido, sabemos que era todavía nuevo al llegar los españoles (Pease 1973: 50-4). A mayor abundamiento, la identificación de los gobernantes incas con el Collao fue tardía y es ya Túpac Yupanqui quien se declara "devotísimo al Sol de la isla Titicaca" (Bouysse-Cassagne 1989: 198).

Por lo demás, este trabajo se circunscribe al análisis del ciclo de los hermanos Ayar, esto es del corpus mítico inca correspondiente a la etapa de los curacas o del señorío sacerdotal.

\section{El mito y la hegemonía sacerdotal Pre-Pachakuti}

El ciclo de los Ayar corresponde, sin duda, a la ideología que sustentó el poder inca en la etapa de los reyes sacerdotales. Pueblos integrantes de una macroetnia, cuya solidaridad se basaba en lazos de parentesco, evolucionaron hasta constituir un señorío regional capaz de instituir un régimen de distribución de prerrogativas, bajo las exigencias del progreso alcanzado en el dominio de los instrumentos de producción. El desarrollo de la agricultura y de la ganadería llevó a organizar de otro modo las fuerzas productivas y las relaciones de producción.

Un proceso muy particular se había producido en siglos anteriores: "Todas las evidencias indican que los teócratas -sacerdotes astrónomos cuyo título, capaca, definía su función-nunca abandonaron su poder en Tiahuanaco" (Sullivan 1996: 209). Éstos nunca habrían recurrido a un ejército como el primer recurso para imponerse, pero su influencia cultural llegó muy al norte, hasta el mismísimo valle del Cusco, antes de que los Wari incursionaran allí.

De manera similar, y al más puro estilo tiawanaquense, los Qhapaq cusqueños, sacerdotes-chamanes, lograron instaurar una organización político religiosa sustentada en su propio prestigio. La expansión de su esfera de influencia pudo basarse, sobre todo, en la atracción de su ideología, aunque su capacidad de control apenas si habría trascendido las fronteras del valle del Cusco durante mucho tiempo.

Por consiguiente, la "épica” de Ayar Cachi y sus hermanos, representa más una expansión en el espacio religioso. Los hermanos Ayar se muestran como demiurgos, héroes fundadores, antes que guerreros. Su ciclo mítico, antes que evocar una gesta militar, 
trasunta un fenómeno de afirmación cultural que deviene en el establecimiento de una subsecuente hegemonía político-religiosa.

"Mango Cápac fue el primero y principio de los ingas que con sus mañas y diligencias se hizo recibir y señoreó sin molestia de por guerra ni armas" (Callapiña, Supno y otros [1542] 1974: 29).

Las grandes agrupaciones "sin orden de guerra ni de campo formado" entraron en la ciudad del Cusco..... "y dijeron que no venían a buscar guerra ni mal alguno sino solamente a buscar tierras buenas a donde vivir y criar ganados" (Montesinos [1644] 1957: 13-4).

Se ha reparado acertadamente en las similitudes que, con respecto a los chamanes, ofrece la imagen de los gobernantes del Tawantinsuyo: "En la cultura andina encontramos un famoso personaje que posee lo esencial de los atributos del chamán amazónico: el Inca. Él fue también un mediador entre los hombres y las fuerzas de lo desconocido. Su poder era fertilizante, regenerador y lo recibía del Sol. Si estaban asociados ambos a un color que simbolizaba su poder, éste era el metal amarillo, el oro" (Ortiz 1987: 23).

La condición chamánica que comparten los Ayar es evidente: Tienen un origen y ancestros comunes, que los hace lloqsimasi por haber salido juntos de la misma paqarina; se consideran huchamasi por la misión que comparten en la tierra conforme a un mandato divino; son sacerdotes, reconocidos como sabios, hamawtas o yatiris; portan un cetro o vara de poder llamada topayawri, y cada uno va premunido de una warak'a u honda hecha de nervios; llevan su tótem familiar <Inti o Wanakawri>, un qoriqenqe o halcón frailesco; y se comunican de distintos modos con el supramundo. Cuando se examina a profundidad estos atributos y los correspondientes gestos de los hermanos Ayar, queda poco de las supuestas correlaciones épicas, alimentarias y culinarias tradicionalmente consideradas. Los hermanos Ayar se muestran, en particular, como héroes sabios, yachaq o amawtas, con señorío político pero relativamente distantes de la función militar.

Es cierto que el pasaje puntual en que el poderoso Ayar Achik derriba cuatro cerros o montañas con sendos hondazos (Betanzos 1999: 18; Urbano 1981: 40), suele interpretarse como un gesto de espíritu guerrero; sin embargo, si se toma en cuenta que los cerros, lugares sagrados o wakas, personifican en el mito a distintas deidades o apus, queda claro que lo que en verdad quiere mostrar el mito es la supremacía religiosa de Wanakawri (Ayar Cachi o Ayar Achik) sobre las wakas locales. ${ }^{2}$

Otro personaje al que se le ha adjudicado atributos guerreros es Mama Wako, hermana y mujer de Ayar Kachi. Mama Wako según diversas versiones es más bien una sacerdotiza, que se comunicaba con las wakas:

"Esta dicha mujer (Mama Wako) que fue gran fingedora y ydulatra hechisera el qual hablaua con los demonios del ynfierno y hazia serimonias y hechiserias y aci hazia hablar piedras y peñas y palos y zerros y lagunas por que le rrespondia los demonios y aci esta dicha señora fue primer enbentadora las dichas uacas ydolos y hecheserias encantamientos" (Guamán Poma 1993: 125).

"Señaló entre todas la mas hermosa muger, y mas sagaz, llamada Mama Huaco, deshonestissima, y lasciua con estremo hizose preñada con ayuda del Demonio, y auindola industriado en lo que auia de hazer, el hijo que parió sin ser sentida de nadie, se lo entregó a vna hermana suya, eminente hechizera, tenida en gran veneración de toda aquella gente" (Salinas y Cordova [1630] 1957: 15).

La expresión Cacha guaco resume la descripción quechua más reiterada de Mama Wako, la que al volcarse al español fue traducida como $<$ mujer varonil, atrevida y libre, que en la

2 Ya se ha advertido que “(...) los oráculos eran de distinto rango jerárquico, posiblemente en referencia a la posición e importancia de la divinidad con la cual era posible comunicarse” (Ziólkowski, 1996: 82). 
cópula acomete al hombre> (Bertonio 1984: 40, 44, 142), descuidando otra significación tal vez menos cotidiana pero sin duda más adecuada: Cacha guaco, cachaguaes o kachawi (comitiva o envío ritual), que son diversos nombres de la Capacocha (Molina 1989: 127-8; Zuidema 1989: 502-3). Aquí cabe anotar, a guisa de hipótesis, que Mama Wako puede muy bien representar una aklla o qhapaq hucha (Capacocha), ofrenda vicarial que habría hecho un largo viaje junto con la comitiva de los Ayar con destino al Cusco o a una waka importante, que pudo buenamente ser el propio Wanakawre. La qhapaq hucha, implícita o subyacente en el relato mítico, pudo haber constituido una especie de pasaporte que permitió a los Ayar trasponer los límites territoriales de diversos pueblos y ocupar nuevas tierras sin recibir represalias.

Los atributos y el abolengo de los héroes salidos de Tamput'oqo guardan cabal consonancia con el sentido etimológico de su nombre común: Ayar. En primer lugar, salta a la vista la lejana procedencia que se les atribuye y el tiempo remoto en que ellos advienen.

En aymara (Bertonio [1612] 1984: 125-6), encontramos:

Haya: Lexos, o lexano.

Haya ccana: Cosa muy clara y manifiesta.

Haya aroma: Muy de noche o de día.

Haya huaru: Muy hondo o alto

Haya manque: Muy hondo

Otros vocabularios aymara consignan:

Jaya: Lejos (Deza 1989: 97).

Jayajaque: Advenedizo, extraño, foráneo (Id.:97)

Jayata: Desde lejos, después de tiempo (Ayala 1988: 108)

En jaqaru (Belleza 1995: 81):

Jaya: Lejos, largo tiempo, mucho rato, lejano, remoto

Jayasa: Antaño, en tiempos antiguos, muchísimo tiempo atrás

Jatatha: De lejos, desde lejos.

La persistencia de la raíz Haya o Jaya en lenguas jaqaru y aymara, cuya separación es anterior a la hegemonía del quechua en el mundo andino, ayuda a describir la lejana procedencia de los hermanos Ayar, en términos del espacio pero también del tiempo, dado que para los propios habitantes del Tahuantinsuyo prehispánico estos personajes ya eran de antaño, de un tiempo remoto. Este perfil de los Ayar es particularmente significativo, ya que "la distancia geográfica y genealógica entre los gobernantes de un Estado y la población cuyo destino rigen, sirve para definirlos como una categoría distinta de seres sociales que heredan legítimamente los derechos y poderes de la élite social" (Bauer 1992: 44).

En quechua (Gonzales Holguín 1989: 156), tenemos también las siguientes expresiones:

Hayaquen allinta rimani: Hablar cosas admirables de buenas, o la lengua muy bien.

Hayaqquen allinta unanchani: Pensar, o entender cosas excelentes

Hayaqquen allinta yachani: Saber muchísimo, de todas cosas bien.

Se desprende de estos enunciados que el vocablo quechua <hayaquen $>$ conlleva una idea de excelencia, pero también de zumo, como en el caso del jugo biliar o hayaqe. En esta línea podemos leer las voces Ayarmaca (Hayamaca) y Ayarwisa (Hayawisa) como equivalentes a $<$ sacerdotes muy sabios $>$. «Los hermanos Ayar» o Haya wawqekuna querría decir más exactamente $<$ los hermanos doctos, los hermanos sapientes $>$, tal como nos lo 
recuerda la tradición oral vertida en las crónicas. Aplicando esta lógica al caso de cada uno de los Ayar podemos recuperar las significaciones siguientes:

Haya achiq: Muy experto en las artes de la adivinación, eximio sortílego, experto adivino.

Haya awtqa o Haya awqa: Muy experto en la confesión, eximio confesor

Haya hucchu: Muy experto en extraer los males, que sorbe o chupa diestramente. Maestro en las artes del onqoy o trance.

Haya manque: Muy hondo, muy secreto, muy profundo en la meditación.

Sobre estas significaciones nos ocuparemos puntualmente en una siguiente entrega. De momento, es preciso considerar que, en otro sentido, la voz ayar parece aludir a la vara de poder, barreta o cetro de oro que portaban los héroes míticos: el topayawri, caxo, o tawna de origen divino.

\section{En Jaqaru:}

Aya: Llevar o traer (palos u objetos alargados no flexibles) (Belleza 1995: 41).

En Aymara:

Ayani: Llevar en las manos una cosa alargada, (Ayala 1988: 77).

Ayaña: Llevar algo oblongo en las manos (Buttner 1984: 22).

Ayaniwaña: Traer rápidamente algo oblongo.

Por lo hasta aquí dicho, no sorprende que los textos recogidos en las crónicas guarden una reveladora correspondencia con los vocablos antes señalados. Los hermanos Ayar, en su condición de sacerdotes-chamanes, disponían de una vara de poder: el topayawri, instrumento fálico que a manera de vara sonajera permite entrar en el mundo del más allá (Ortiz 1987: 21). La adivinación por medio de una vara (marcada con ciertos signos) que se arroja al aire, forma parte de diversas tradiciones chamánicas, como en el caso de los samoyedos (Eliade 1996: 189).

“(Manqo Qhapaq)... hizo su conçierto con sus hermanos para buscar tierras, tomando sus bestidos rricos y armas, sacando aquel palo que abía dejado el dicho Tunapa, el cual palo se llamó tupa yawri” (Pachacuti 1993: 194).

“... dizen que aquel dicho palo que <avían> dejado el dicho Tunapa, entregándoles en las manos del dicho Apo Tambo, se conbertía en oro fino en el nacimiento de su desendiente, llamado Manco Capac Inca" (Pachacuti, Id.: 193).

"Después de esto estuvieron en Matagua dos años, intentando pasar el valle arriba a buscar buena y fértil tierra. Mama Guaco, que fortísima y diestra era, tomó dos varas de oro y tirólas hacia el norte. La una llegó como dos tiros de arcabuz a un barbecho llamado Colcabamba y no hincó bien, porque era tierra suelta y no bancal; y por esto conocieron que la tierra no era fértil. Y la otra llegó más adelante cerca del Cusco y hincó bien en el territorio que llaman Guanaypata, de donde conocieron ser tierra fértil. Otros dicen que esta proeba hizo Mango Capac con la estaca de oro que traía consigo, y que así conocieron la fertilidad de la tierra" (Sarmiento 1988: 38).

Queda sólo indicar que el tupayawri tenía ciertas inscripciones que fueron leídas por el sacerdote de la waka de Saño, como se verá más adelante, lo que confirma un rasgo típico de la vara chamánica. ${ }^{3}$ Los relatos del ciclo mítico que examinamos indican que el tupayawri fue depositado en el Qorikancha o Casa del Sol.

3 "El uso de báculos para la adivinación está comprobado en el Perú, por los documentos arqueológicos desde épocas muy tempranas. En el complejo monumental de Huaca de los Ídolos, valle de Supe (2750 a.C.) se encontraron 135 báculos decorados con motivos geométricos grabados, usados probablemente por algún tipo de técnica oracular" (Burger 1992: 36, 39; citado por Polia 1999: 311). 
Además del tupayawri, distintivo de poder y símbolo chamánico, los Ayar llevaban consigo otros elementos emblemáticos: las warak'a u hondas y un ave, el indi o qoriqenqe. La honda o waraka (en quechua) homologa a los Ayar con el hondero celestial que lanza estrellas en raudo recorrido por el cielo nocturno. Waraja significa precisamente $<$ estrella $>$ en jaqaru, al igual que wara wara en aymara y a las piedras de adivinación que poseen los chamanes andinos actuales se les llama también <estrella $>$.

Los Ayar salen juntos de la misma paqarina, conocida como Qhapaq T'oqo (situada en Tamput'oqo o Paqareqtambo), de aquí su condición de lloqsimasi. Según el mito, ellos tenían una tarea o negocio común por mandato divino, compromiso compartido que los hacía huchamasi o copartícipes. Puede interpretarse este episodio del mito como representación de una alianza fraterna que ligaba a curacazgos identificados por el culto a un ancestro o mallki común.

"Manco Cápac salió de Pacaritambo con los viejos sacerdotes y su familia, llevando consigo la guaca e ídolo llamado Guanacaure" (Callapiña, Supno y otros [1542] 1974: 26).

"Y Mango Capac traía consigo un pájaro como halcón llamado indi, al cual veneraban todos y le temían como a cosa sagrada, o, como otros dicen, encantada" (Sarmiento 1988: 54).

"Cuentan déste [Mayta Cápac] que como el pájaro indi, que Manco Cápac había traído de Tampu-Tocco, lo hubiesen heredado los sucesores suyos, y antes desde Mayta Cápac siempre lo habían tenido cerrado en una petaca o cajón de paja, que no la osaban abrir, tanto era el miedo que le tenían, mas Mayta Cápac, como más atrevido que todos, deseoso de ver qué era aquello que tanto guardaron sus pasados, abrió la petaca y vido el pájaro indi y habló con él; ca dicen que daba oráculos. Y de aquella confabulación quedó Mayta Cápac muy sabio y avisado en lo que había de hacer y de lo que le debía de suceder" (Sarmiento 1988: 69; Lothrop 1964: 41).

“Asimesmo, llevaron un ídolo de piedra de figura de hombre y diez u doce indios con sus mujeres, muy industriados a los fingimientos con el Mango Cápac, como familia suya, con el ídolo nombrado Guanacuare por delante; ansí el cerro y serranía adonde hicieron alto, se quedó con el nombre del ídolo nombrado Guanacaure" (Callapina, Supno y otros 1974: 24).

Los seres alados de la familia de los cóndores (kunturi) y los halcones (wamani) simbolizan la condición divina de los personajes. La asociación a pequeñas aves (cernícalos, loros, picaflores, etc.) tiene el doble propósito de acentuar el papel de hijos o personajes menores dotados de capacidad de comunicación. Las divinidades hablan, se comunican entre sí y con los hombres (Sánchez 1995: 178).

Kuntur o kunturi: Q. y Ay. El cóndor.

Mamani o wamani: Q. y Ay. El halcón.

Anka, paka o apaka: Q. y Ay. Águilas (Gonzales Holguín 1989: 268; Bertonio 1984: 141).

Cocotaapaca o cunturaapaca: Ay. Una especie de paca muy grande, poco menor que buitre

Curiquenque: Q. y Ay. Otra paca de cola blanca.

Allqamari Qoriqenqe: Q. Pájaro blanco y negro, del tamaño de gallina, siempre anda acompañado y vive en la sierra (GH., Id.: 19; Bertonio, Id.: 141).

Yana chucu paka: Otra que es toda negra.

Cchekhe paka: Es entreverada de negro y pardo.

Llulla paka: Q. El aguilucho que ponen para que acudan las águilas grandes, y den en el lazo que les está armado allí cerca. 
Ahuancana o awankana: Otro género de águila.

Qusqu: Ay. Buitre (Buttner 1984: 179).

Huacamaya ahua: Papagayo grande (GH. Id.: 614).

Vritu: Q. Papagayo mediano (GH. Id.: 614).

Caqque, kaqe o k'aki: Ay. Pájaro grande y negro (Bertonio Id.: 37). ¿Tucán?

Kalla kalla: Ay. Periquito, paxaro (Bertonio, Id.: 45)

Calla: Q. Papagayllos, o periquillos (GH. Id.: 614)

El qoriqenqe mítico es descrito como un hermosísimo pájaro de dorado plumaje con vetas azules, amarillas y rojas, que revelaba el futuro. Según la tradición, aparecía cada cien años y daba a su dueño poder, sabiduría y fortuna. Citando al canónigo Rendón, dice Alfonsina Barrionuevo que:

"Wayna Qhapaq dividió en Tumibamba la sagrada insignia (el qoriqenqe) que estuvo colocada en la corona real o maskapaycha y envió al Cusco las plumas amarillas y azules para su hijo Waskar, entregando las rojas a Atawallpa" (Barrionuevo 1980: 174-5).

Como sacerdotes, los Ayar habrían tenido éxito en la consolidación de su señorío, entre otras razones, porque eran poseedores de un saber filosófico-especulativo unido a conocimientos técnico-organizativos o instrumentales apropiados. La tarea que los hermanos Ayar llevan adelante parece expresar la coronación de un proceso de cambio ideológico ya iniciado, al que hace referencia el mito de Tonapa o Tunupa.

El ciclo de los Ayar se corresponde precisamente con el marco ideológico del señorío sacerdotal que tuvo vigencia hasta Pachakuteq. De algún modo, los mensajes cifrados en los mitos operaron a manera de textos sagrados que debían ser observados en el proceso de sucesión de los gobernantes incas (Ziolkowski 1984: 46). Las visiones y sueños de los aspirantes al trono, los diversos rituales que precedían a la designación del sucesor (estadía en un lugar sagrado, ayunos, ofrendas, etc.), y los acontecimientos subsecuentes (elaboración de las figuras de los wawqe, cambio de nombre), replican de diversos modos los mensajes, códigos y episodios del mito. El mito condensa así las diversas etapas del proceso de aprendizaje e iniciación cultural de los príncipes pretendientes a la dignidad de sapan inka o soberano único.

Entre los elementos chamanísticos que se hallan presentes en el ciclo de los Ayar, y que eran de observancia en la iniciación cultural de los soberanos incas, sobresalen los siguientes:

- Producción de mensajes con carácter predictivo-profético, como los emitidos por Wanak'awri.

- Observación del vuelo de las aves, del Qoriqenqe o del propio Awqa en figura de buitre.

- Observación de fenómenos naturales, en especial del arco iris deificado con el nombre de Tulumanya o K'uychi.

- Adivinación mediante la interpretación de sueños o musqhoy, visiones llamadas ramca o sanca (Gonzales Holguín 1989: 311), y la aplicación de diversas técnicas de echar suertes, por ejemplo con maíz y estiércol de ganado.

- Experiencias místicas y de éxtasis chamánico a través de introspección, ayunos, privaciones, agotamiento, absorción de alucinógenos y embriagantes, y con el uso de cristales (Ziolkowski 1984: 45).

\section{Los Ayar y el antiguo sacerdocio andino}

La calidad sacerdotal de los hermanos Ayar está reiteradamente señalada en diversas versiones del mito. Algunos relatos indican que Ayar Manco iba acompañado por ancianos 
sacerdotes, sus maestros e iniciadores, lo cual es particularmente significativo y coherente porque en el mundo andino la ancianidad presupone sabiduría. De Manco Qhapaq, dice el mito que fue criado por venerables sacerdotes y que llevó consigo a uno de los dos viejos, tenidos en gran veneración como sacerdotes, de los ídolos de Apotambo (Callapiña, Supno y otros [1542] 1974: 24). Otros relatos puntualizan la calidad de sacerdotisas que tuvieron las encargadas de criar a Ayar Manco: Mama Huaco era hechicera, hablaba con los demonios, hacía hablar a las piedras y a las peñas (Guamán Poma 1993: 125). Mama Huaco (Mama Wako) entregó el hijo que parió sin ser sentida a una hermana suya, eminente hechicera tenida en gran veneración de aquella gente, llamada Pilcosiza (Salinas y Córdova [1630], en Urbano 1981: 130-1). En estas y otras versiones, la tradición oral remarca el conocimiento y la excelencia de los héroes culturales, que tienen como misión establecer la cabeza de un nuevo reino.

Los sacerdotes hallaban por sus coorpilares que Manco Qhapaq sería señor de la tierra. Los sacerdotes efectuaban el ritual del kallparikukuy, llaqwar o llachuar. Hoy en la fiesta católica del Corpus se acostumbra consumir un plato típico, tradicional, conocido como llaqway uchu, que al parecer es una reminiscencia de la comida preparada con motivo del antiguo llachuar. En la fiesta de la sitwa se examinaban los bofes de los animales sacrificados, todos los extranjeros salían de la ciudad del Cusco y volvían a ella una vez cumplidos los rituales de purificación; a su regreso, los extranjeros y visitantes eran agasajados con sankhu (onqoy mita).

De esta manera, los mitos ponen de manifiesto que los héroes fundadores del Tawantinsuyo ostentaban una alta posición dentro de la jerarquía sacerdotal al momento de dejar su waka de origen o paqarina (probablemente la que correspondía a amawtas, tal vez wisas, o mejor kuntiwisas, si se tiene en cuenta que Paqareqtampu pertenecía al espacio kunti del mundo por entonces conocido). Ayar Awqa al asentarse en el mojón de la antigua Akamama o Qosqo debió pasar a ser un Qosqowisa (Pachacuti 1993: 215, 259).

El mito contiene referencias a los antiguos conceptos mágico-religiosos. Da cuenta sobre la más compleja estructuración que alcanza el sacerdocio a partir de los Ayar. Las funciones antes concentradas en el chamán o kuraka se diversifican y, en esta misma medida, los grados superiores del 'saber' se van haciendo accesibles sólo a determinados funcionarios del culto, miembros de una jerarquía cuya cúspide ocupaban el willaq umu o sumo sacerdote y el propio sapan inka.

\subsection{Los wisa o sumos sacerdotes}

Los vocablos Altomisa y Pampamisa (y, por consiguiente, las denominaciones de Altomesayoq y Pampamesayoq), que corresponden a especialistas chamanes del mundo andino están ligados, de modo evidente, a la voz wisa. Sabemos que uisa quiere decir <persona como profeta sea falso o verdadero>, y uissa en la lengua del Cusco es el que nace con otro de un vientre (Pachacuti 1993: 207). Siendo el término wisa propio de las lenguas andinas prehispánicas, la asociación de los rituales chamánicos contemporáneos con los vocablos "mesa" y "misa" del castellano es, sin duda, producto de una traslación idiomática muy posterior (Sánchez 2009: 77-96).

\section{El ceremonial de la kallpa}

Como sacerdotes wisa, los Ayar eran principales maestros y guías en la ejecución de diversas ceremonias y rituales, entre las cuales la del kallparikukuy tiene particular significación. Según Gonzales Holguín (1989: 44), el concepto andino de kallpa iba más 
allá de la simple fuerza física del hombre o de cualquier ser vivo. Este concepto se extendía a las “potencias" y “poder” del alma y del cuerpo. El ánimo y el brío de la persona constituían parte de su kallpa, el valor para la guerra era también una manifestación de esta fuerza. A la ceremonia consistente en "ver" o examinar la kallpa, se le denominaba kallparikukuy (voz compuesta que viene de kallpa=fuerza y rikukuy=mirarse) o kallpatarikusun (de kallpata=la fuerza y rikusun=vamos a ver). La "fuerza" era examinada en las vísceras de animales sacrificados que, según la importancia y propósito del ritual, podían ser llamas, alpacas e incluso cuyes. ${ }^{4}$

El calparicuqui (kallparikukuy): "quiere decir, los que ven la ventura y suceso que habían de tener las cosas que les preguntaban". Hinchaban soplando los bofes de aves, 'corderos y carneros' (camélidos americanos) e interpretaban las señales que en ellos hallaban (Molina [1574-75] 1989: 62-3).

"Hacían el llachuar ques matando una llama gentilmente metiendo una mano por el ijar del carnero, sacándole el corazón y bofes palpitando, soplando los bofes, en que, por ciertas señales, sabían lo que había de suceder" (Hernández Príncipe 1923: 42).

"Acabada la fiesta suelen en algunas partes sacrificar unos cuyes, y ver por la sangre que corre en las entrañas a tal, o tal parte si han ayunado bien, y guardado todas las ceremonias de la fiesta, y a esta última llaman Callpataricusum" (Villagómez [1649], en Toro 1991: 158).

Un documento de 1656 describe la siguiente práctica en Cajatambo:

"Quando les hazen las pacarinas a los difuntos los ponen en sus casas sentados en cuclillas puestas las manos en la boca matan una llama y de la mejor carne se la ponen delante al difunto y los bofes los soplan por el garguero que llaman tara riquim puru riquin y se hincan dhos bofes como odre y paresen como unos nudos begigas y luego salen diziendo que se an de morir presto algunos de sus parientes más cercano" (Duviols, 1986: 63).

Otra información aún más antigua (1614) consigna que en la provincia de Chinchaycocha

“... sacaban los bofes y los soplauan por el caño del tragadero y como los bofes son esponjosos se hinchauan llenandose de uiento y si quedaban lisos sin ninguna grieta ni quebradura era buena señal y dauan la respuesta de prospero succeso y si auia alguna grieta o quebradura era mal agüero y dauan la respuesta adversa" (Polia 1999: 357).

En este sentido, el episodio mítico en que Mama Wako le saca los bofes a un indio Walla y los hincha soplándolos (Sarmiento 1988: 60; Murúa 2001: 47; Harvey 1994: 20), no estaría registrando un acto de ferocidad guerrera sino un gesto eminentemente mágico y ritual. Es plausible que el relato quiera recordar que Mama Wako ejecutó el ritual del kallparikukuy. Además, Mama Wako habría usado el Tumi para sacrificar al hombre, y este instrumento era desde tiempos preíncas de uso eminentemente ritual (Cabello Valboa [1586] 1951). No es gratuito que las crónicas refieran a Mama Wako como una eminente hechicera; de manera que su acto, antes que por su ferocidad guerrera, debió tener gran efecto por tratarse de un gesto poderoso en el dominio sobrenatural. Los resultados de su acto adivinatorio debieron constituir señales incontrovertibles sobre la voluntad de las divinidades pues, al parecer, Mama Wako hizo un típico kallparikukuy (observación de las fuerzas), un acto adivinatorio en vísceras humanas.

4 Polia consigna la práctica de haruspicina con el cuy sacrificado soplando en la tráquea del animal y llenando sus pulmones de aire (Polia 1999: 113). 


\section{Las distintas funciones sacerdotales y la determinación del "elegido"}

Según el mito, los cuatro hermanos Ayar debían definir sus funciones. En esta definición fueron decisivas las cualidades de cada uno de ellos. Los Ayar hicieron lo que se conoce como el kamankuni o camancuni, esto es el reparto entre sí de tareas y otros quehaceres. Hecharon suertes en Guana cauri, el cerro que llegaba al pie de la huaca (Murúa [1590] 2001: 39-42)

“... y llegaron a un pueblo llamado Quirimanta, al pie de un cerro que después llamaron Guanacauri. Y en este pueblo consultaron cómo dividirían entre sí los oficios de su viaje, para que entre ellos hubiese distinción" (Sarmiento [1572] 1988: 56).

Cada uno de los hermanos poseía una habilidad chamánica excepcional que lo calificaba para ser elegido por la divinidad: adivinación, poder de sanación, liberación de la culpa contaminante e introspección. El reparto de tareas que convienen los Ayar, determina el destino ulterior de cada uno de ellos: Kachi es ofrendado a la paqarina de origen, Uchu pasa a ser ídolo y waka protectora de los suyos, Awqa se ubica como piedra señal de posesión u omphalus en el Cusco y Manko Qhapaq funda el señorío destinado a convertirse en el Tawantinsuyo.

Los gestos de los Ayar pasan a ser arquetipos que serán repetidos en el proceso de educación e iniciación religiosa de los príncipes incas, así como en la elección de cada nuevo sapan Inca. En una entrega posterior hemos de examinar detenidamente las funciones sacerdotales diferenciadas que la mitología reconoce a cada uno de los hermanos Ayar, los lloqsimasikuna, esto es los paridos por una misma madre o salidos de una misma paqarina.

\section{Bibliografía}

\section{ALBORNOZ, Cristóbal de}

1989 "Instrucción para descubrir todas las guacas del Piru y sus camayos y haziendas" [1581 a 1585]. En Fábulas y Mitos de los Incas (C. de Molina y C. de Albornoz), editado por Henrique Urbano y Pierre Duviols. Crónicas de América 48. VIERNA S.A. Madrid.

AYALA LOAYZA, Juan Luis

1988 Diccionario Español-Aymara Aymara-Español. Edit. Juan Mejía Baca. Lima, 1988.

BARRIONUEVO, Alfonsina

1980 Cusco mágico. Edit. Universo, Lima.

BAUER, Brian S.

1996 El desarrollo del estado inca. Edit. CBC, Cusco.

1992 "Pacariqtambo y el Origen Mítico de los Incas". En Avances en Arqueología Andina, Centro de Estudios Regionales Andinos. Cusco.

BELLEZA CASTRO, Neli

1995 Vocabulario Jacaru-Castellano (Aimara Tupino). CBC, Cusco.

BERTONIO, Ludovico

1984 Vocabulario de la lengua Aymara [1612]. CERES/ IFEA, Cochabamba. BETANZOS, Juan de

1984 Suma y narración de los Incas [1551]. UNSAAC (Transcripción por María del Carmen Rubio), Cusco 1999. 
BOUYSSE-CASSAGNE, Therese

1989 “Comentarios a Urton”. En Revista Andina, Año 7, № 1. Cusco.

BUTTNER, Thomas y CONDORI, Dionisio

1984 Arunakan liwru. Diccionario Aymara-Castellano. PEEBP, Puno.

CABELLO VALBOA, Miguel

1951 Miscelánea Antártica [1586]. Instituto de Etnología. UNMSM, Lima.

CALLAPIÑA, SUPNO y otros.

1974 Relación de la descendencia, gobierno y conquista de los incas [1542]. (Relación de los Quipucamayos a Vaca de Castro). Edic. Biblioteca Universitaria, Lima.

COBO, Bernabé

1956 Historia del Nuevo Mundo [1653]. BAE 91-92, Madrid.

CHOY, Emilio

1978 "Desarrollo del pensamiento especulativo en la sociedad esclavista de los incas". En Los modos de producción en el imperio de los Incas de Waldemar Espinoza Soriano. Mantaro, Lima.

DEZA GALINDO, Juan Francisco

1989 Diccionario Aymara-Castellano Castellano-Aymara. Graphos 100 Editores, Lima.

DUVIOLS, Pierre

1986 Cultura andina y represión. Procesos y visitas de idolatrías y hechicerías en Cajatambo, siglo XVII. CBC, Cusco.

ELIADE, Mircea

1996 El chamanismo y las técnicas arcaicas del éxtasis. Fondo de Cultura Económica, México.

ESPINOZA SORIANO, Waldemar

1997 Los Incas. Economía, sociedad y Estado en la era del Tahuantinsuyo. Amaru Editores, Lima.

GONZALES HOLGUÍN, Diego

1989 Vocabulario de la lengua general de todo el Perú, llamada lengua Qquichua o del Inca [1608]. UNMSM, Lima.

GUAMÁN POMA DE AYALA, Felipe

1993 Nueva corónica y buen gobierno [1615]. Fondo de Cultura Económica, Lima.

HARVEY VALENCIA, Armando

1994 Coricancha. El gran templo del Sol. UNSAAC, Cusco.

HERMO, José María

1899 La Madre de los Sueños. Tip. Comercial, La Paz.

HERNÁNDEZ PRÍNCIPE, Rodrigo

1923 Mitología Andina. En Revista Inca, Vol. 1. Lima.

KAUFFMAN DOIG, Federico

1975 Historia de los peruanos. El Perú antiguo. Peisa, Lima.

LOTHROP, Samuel K.

1964 El tesoro del Inca. UNMSM, Lima.

LUMBRERAS, Luis

1977 “Acerca de la aparición del Estado Inka”. En Cuadernos 24-25. CONUP, Lima.

MARZAL M., Manuel

1979 "Funciones religiosas del mito en el mundo andino cuzqueño". En Debates en Antropología $\mathrm{N}^{\circ}$ 4, Lima. 
MILLONES, Luis

1975 "Sociedad indígena e identidad nacional”. En Perú: Identidad nacional. CEDEP, Lima.

MOLINA, Cristóbal de (El Cuzqueño)

1989 Fábulas y ritos de los Incas (1574-75). Historia 16, Madrid.

MONTESINOS, Fernando de

1957 Memorias antiguas historiales y politicas del Perú [1644]. H. G. Rozas, Cusco.

MURÚA, Fray Martín de

2001 Historia General del Perú. Dustin. Edición de Manuel Ballesteros, Madrid.

NUÑEZ ANAVITARTE, Carlos

1978 “Teoría del Desarrollo Incásico". En Los modos de producción en el imperio de los Incas de Waldemar Espinoza Soriano. Mantaro, Lima.

ORTIZ RESCANIERE, Alejandro

1987 “El Inca y el Chamán”. En Anthropologica N 5. PUC, Lima.

PACHACUTI, Juan de Santa Cruz

1993 Relación de antigüedades deste reyno del Piru [1613]. Estudio etnohistórico de Pierre Duviols y César Itier. IFEA/ CBC, Cusco.

PEASE, Franklin

1973 El Dios Creador Andino. Mosca Azul Editores, Lima.

POLIA MECONI, Mario

1999 La Cosmovisión Religiosa Andina, en los documentos inéditos del Archivo Romano de la Compañia de Jesús 1581-1752. PUCP, Lima.

PORRAS BARRENECHEA, Raúl

1973 Mito, tradición e historia del Perú. Edic. Retablo de Papel, Lima.

RICARDO, Antonio

1951 Vocabulario y phrasis en la lengua general de los indios del Perú, llamada Quichua [1586]. UNMSM, Lima.

ROSTWOROWSKI, María

1988 Estructuras andinas del poder. IEP, Lima.

SALINAS Y CÓRDOVA

1957 Memorial de las Historias del Nuevo Mundo [1630]. Col. Clásicos peruanos, Lima.

SÁNCHEZ GARRAFA, Rodolfo

2009 "Los wisa: principales intérpretes del culto y las prácticas curativas en los Andes". En Medicina Tradicional Andina. Planteamientos y aproximaciones.

1983 “QQué es el mito?”. En Rev. Anthropológica N 1, PUCP. Lima.

SÁNCHEZ, Ricardo y SÁNCHEZ, Rodolfo (Editores). CBC / CMA, Cusco.

1995 "Espacio y estructuras religiosas en los mitos de Awsangate". En Rev. Anthropologica $\mathrm{N}^{\circ} 13, \mathrm{PUC}$, Lima.

SARMIENTO DE GAMBOA, Pedro

1988 Historia de los Incas. Miraguano \& Polifemo, Madrid.

SULLIVAN, William

1996 The secret of the Incas. Mith, Asttronomy, and the War Against Time. Crown Publishers, Inc. New York.

TAMAYO, José

1985 Nuevo Compendio de Historia del Perú. Lumen, Lima. 
TORO MONTALVO, César

1991 Mitos y leyendas del Perú. Tomo II. AFA Editores, Lima.

URBANO, Henrique O.

1992 "Sincretismo y sentimiento religioso en los Andes. Apuntes sobre sus orígenes y desarrollo". En Ética y teología ante el Nuevo Mundo. Valencia y América. Actas del VII Simposio de Teología Histórica (abril, 1992). (1991) "Historia y etnohistoria andinas". En Revista Andina, Vol. 17. CBC, Cusco. (1988) "En nombre del dios Wiracocha... Apuntes para la definición de un espacio simbólico prehispánico". Revista Allpanchis N³2, Cusco. (1981) Wiracocha y Ayar héroes y funciones en las sociedades andinas. CBC, Cusco.

URTON, Gary

1989 "La historia de un mito: Pacariqtambo y el origen de los Incas". Revista Andina, Año 7, $\mathrm{N}^{\circ}$ 1. Cusco.

VALCÁRCEL, Luis E.

1959 Etnohistoria del Perú Antiguo. Edit. San Marcos, Lima.

1939 “Sobre el origen del Cusco". En Revista del Museo Nacional N², Lima.

VILLAGÓMEZ, Pedro de

1919 Exortaciones e instrucción acerca de las idolatrías de los indios del Arzobispado de Lima. Imprenta y Librería Sanmartí y Ca. Lima.

ZIOLKOWSKI, Marius S.

1984 “Algunos aspectos de la educación e iniciación religiosa de los príncipes incas". En Rev. Anthropológica $\mathrm{N}^{\circ}$ 2, PUCP, Lima.

ZUIDEMA, Tom.

1989 Reyes y guerreros. Fomciencias, Lima. 